\title{
Anne Marie Miraglia, Des Voix contre le silence
}

\section{Ilaria Vitali}

\section{(2) OpenEdition}

\section{Journals}

\section{Edizione digitale}

URL: https://journals.openedition.org/studifrancesi/46359

DOI: 10.4000/studifrancesi.46359

ISSN: 2427-5856

\section{Editore}

Rosenberg \& Sellier

\section{Edizione cartacea}

Data di pubblicazione: 1 octobre 2007

Paginazione: 484

ISSN: 0039-2944

\section{Notizia bibliografica digitale}

|laria Vitali, «Anne Marie Miraglia, Des Voix contre le silence», Studi Francesi [Online], 152 (LI | II) | 2007, online dal 30 novembre 2015, consultato il 24 novembre 2021. URL: http://journals.openedition.org/ studifrancesi/46359; DOI: https://doi.org/10.4000/studifrancesi.46359

\section{Questo documento è stato generato automaticamente il 24 novembre 2021.}

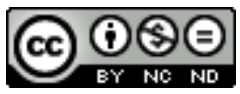

Studi Francesi è distribuita con Licenza Creative Commons Attribuzione - Non commerciale - Non opere derivate 4.0 Internazionale. 


\title{
Anne Marie Miraglia, Des Voix contre le silence
}

\author{
Ilaria Vitali
}

\section{NOTIZIA}

ANNE MARIE MIRAgLIA, Des Voix contre le silence, French Series FM28, Durham, University of Dhuram, 2005, pp. 157.

1 Questo volume della collana "French Monographs" della University of Durham si propone di fondere la riflessione sul genere dell'autobiografia con i Gender Studies, sottolineando il valore e l'importanza del «je» nella letteratura femminile del Maghreb contemporaneo. Per porre le basi del suo studio, Anne Marie Miraglia apre il testo con una citazione da Assia Djebar: «Toute femme écrivant qui s'avance ainsi hardiment prend le risque de voir combien son chemin est miné» (p. 1).

2 Partendo da questo principio, il primo capitolo del volume, «Contexte social et culturel», traccia le linee contestuali della letteratura in questione, affrontando alcuni dei temi chiave che hanno segnato la realtà femminile maghrebina, come la segregazione e le difficoltà nel briser le silence attraverso la scrittura autobiografica, spesso interpretata dalla cultura dominante come esibizionismo. La prima vera e propria analisi testuale è affrontata nel secondo studio, «Derives identitaires dans Chronique frontalière», sull'opera della tunisina Emna Bel Haj Yahia, sottolineandone la straordinaria forza autobiografica che diviene denuncia sociale. Il terzo, "Quête d'identité chez M. Ben et F. Boucetta», tocca invece il tema dell'engagement e del passaggio dalla terza alla prima persona, attraverso due romanzi, Sabrina, ils t'ont volé ta vie dell'algerina Myriam Ben e Anissa captive della marocchina Fatima Boucetta.

Il quarto e il quinto saggio, «Je(u)x subversifs dans l'ombre des sultanes» e «Les Nuits de Strasbourg et la jouissance fémmine», sono incentrati sull'opera di Assia Djebar, la più nota autrice maghrebina, i cui romanzi toccano molteplici temi della condizione della donna musulmana, come il suo particolare rapporto con il corpo e lo spazio. Il romanzo 
Ombre sultane affronta simultaneamente il racconto di due donne attraverso un monologo interiore, il discorso di Isma rivolto a Hajila, la nuova sposa scelta dal marito. La particolarità della strategia testuale del racconto, racchiusa nell'alternanza costante tra «je» e «tu», tratta così in modo singolare il tema della sessualità e della coppia. Il sesto capitolo, «Des Bâtards, du silence et des mensonges», avvicina temi ancor più scottanti, come quello dei figli illegittimi, dello stupro e dell'incesto, visti dal punto di vista femminile. L'ultimo capitolo, «Les Masques du silence dans deux récits d'enfance beure», sposta infine l'attenzione sulla cosiddetta letteratura «beure», ovvero quella dei figli (qui le figlie) di immigrati in Francia, concentrandosi sui racconti d'infanzia di due scrittrici di origine maghrebina nate a Parigi, Farida Belghoul e Tassadit Amache, che sfruttano le particolarità del racconto autobiografico per illuminare la questione identitaria e descrivere il singolare «terzo spazio» che abitano. Un saggio di sicuro interesse, corredato da una bibliografia dettagliata, che approfondisce in modo non scontato la singolarità della condizione femminile maghrebina in un'epoca di grandi cambiamenti, analizzandone particolarità e contraddizioni. 